\title{
A PRODUÇÁO DAS CONSOANTES OCLUSIVAS DO INGLÊS POR FALANTES NATIVOS E BRASILEIROS: A : RELAÇÃO ENTRE DURAÇÃO E SOLTURA
}

\section{THE PRODUCTION OF THE ENGLISH PLOSIVE CONSONANTS BYNATIVEANDBRAZILIANSPEAKERS: THE RELATION BETWEEN DURATION AND RELEASE}

\author{
Michael Douglas Silva Dias ${ }^{1}$ \\ Consuelo de Paiva Godinho ${ }^{2}$ \\ Vera Pacheco ${ }^{3}$
}

Universidade Estadual do Sudoeste da Bahia

\section{RESUMO}

Em termos de produção e realização, os segmentos oclusivos em inglês apresentam um comportamento fonético-fonológico bastante característico, podendo ser produzidos com soltura audível, com soltura audível moderada, sem soltura audível ou, até mesmo, podem não ser produzidos, caracterizando apagamento. Partindo do pressuposto de que brasileiros aprendizes de inglês tendem a transferir para a L2/LE os padrões de produção de sua L1, o principal objetivo deste artigo é verificar como se dá a produção das consoantes oclusivas do inglês por parte de três brasileiros aprendizes de inglês como língua estrangeira em nível inicial, no que se refere à duração e à soltura destas consoantes em posição de onset e coda, em palavras com estrutura silábica CVC. Nossos dados revelaram que a duração das consoantes oclusivas em posição de coda supera consideravelmente a duração das oclusivas em posição de onset por brasileiros. Além disso, devemos ver a produção de oclusivas com soltura audível por parte de aprendizes como formas também

1 Mestre em Linguística pela Universidade Estadual do Sudoeste da Bahia (UESB), e-mail: maicondsilva@hotmail.com

2 Doutora em Linguística (UNICAMP), e-mail: consuelopaiva@gmail.com

3 Pós-doutora em Linguística (UNESP), Universidade Estadual do Sudoeste da Bahia (UESB), e-mail: vera.pacheco@gmail.com 
: possíveis na L2, e não como formas que precisam ser erradicadas em um

: contexto de ensino-aprendizagem.

PALAVRAS-CHAVE: Fonética do Inglês; Fonologia; Oclusivas; Duração Segmental; Soltura.

\section{ABSTRACT}

In terms of production and realization, the plosive segments in English show a rather peculiar phonetical-phonological behavior, being produced with an audible release, a moderate audible release, with no audible release or not even being produced, which characterizes deletion. Taking into account the fact that Brazilian English learners tend to transfer to the L2/FL the production patterns of their L1, the main goal of this article is to verify how three Brazilian English learners in the beginning stage produce the plosive consonants in English, concerning the duration and release of these consonants in onset and coda positions, in words with CVC syllabic structures. Our data revealed that the duration of plosive consonants in coda position is considerably higher than the duration of plosive consonants in onset position, by Brazilians. Besides, we must encounter the production of plosives with audible release by learners as possible productions in the L2, and not as productions that should be eradicated in the teaching-learning context.

KEYWORDS: English Phonetics; Phonology; Plosives; Segmental Duration; Release.

\section{INTRODUÇÃO}

Diversos trabalhos têm sido desenvolvidos recentemente no que se refere aos segmentos consonantais em posição de onset e coda silábicos em língua inglesa, por parte de aprendizes de inglês como segunda língua/ língua estrangeira (ABRAMSON; TINGSABADH, 1999; BETTONITECHIO, 2005; DAVIDSON, 2011; FULLANA; MORA, 2009; SOLÉ, 2003). Estas pesquisas estudam o componente fonético-fonológico do inglês com base em suas realizações fonéticas e configurações fonotáticas, as quais são sistematicamente distintas dos padrões existentes no português brasileiro (doravante PB). Um fenômeno bastante recorrente no inglês diz respeito à ocorrência de consoantes oclusivas (bilabiais [p], [b] / alveolares 
$[\mathrm{t}]$, [d] / velares $[\mathrm{k}],[\mathrm{g}]$ ) em coda silábica final, o qual, por sua vez, não ocorre no português. Quando do aprendizado do inglês como língua estrangeira, este fator pode gerar contexto para processos de apagamento ou ressilabificação, no caso de epêntese vocálica (AVERY; EHRLICH, 1992; PEROZZO, 2013).

Segundo Perozzo (2013), em termos de produção e realização, os segmentos oclusivos apresentam um comportamento fonético-fonológico bastante característico, podendo ser produzidos com soltura audível, com soltura audível moderada, sem soltura audível ou, até mesmo, podem não ser produzidos, caracterizando apagamento (DAVIDSON, 2011).

A manifestação fonética da não soltura audível em codas finais do inglês pode implicar dificuldades para os aprendizes brasileiros identificarem e distinguirem determinadas consoantes oclusivas quando da fala contínua, devido ao aspecto contínuo e discreto desta. Abramson e Tingsabadh (1999) exemplificam este fator a partir das palavras rap ['ræp], rack ['ræk] e rat ['ræt], as quais, se forem produzidas com a realização das oclusivas em coda sem soltura audível, podem não ser interpretadas como perceptualmente distintas pelos aprendizes brasileiros, visto que a não soltura do item na coda possivelmente minimize o entendimento do item lexical a que se refere.

Levando-se em consideração que, no inglês, as consoantes oclusivas, quando em coda, podem ser produzidas de maneiras distintas (com soltura, sem soltura, soltura moderada), pergunta-se: como os brasileiros aprendizes de inglês produzem estes segmentos, em onset e em coda silábicos? As hipóteses aqui levantadas são as seguintes:

(1) o falante nativo do inglês produz de maneiras diferentes a mesma consoante estando em onset ou em coda na sílaba; ou seja, numa palavra como bob ['bab], a oclusiva bilabial [b] em posição de onset apresentaria uma duração maior que a mesma oclusiva em posição de coda. Essa hipótese advém do fato de que, apesar de não constituir uma regra categórica no inglês, as oclusivas em posição de coda final tendem a ser produzidas sem soltura audível;

(2) o falante brasileiro produz da mesma maneira estas consoantes em onset e em coda, já que não possui esse uso para as consoantes em coda em sua L1; ou seja, numa palavra como bob [’bab], a oclusiva bilabial [b] em posição de onset apresentaria uma duração igual/ similar à duração da mesma oclusiva em posição de coda; 
(3) as consoantes em posição de coda produzidas por brasileiros aprendizes de inglês apresentam valores que são próximos ou iguais aos valores das consoantes em posição de onset produzidas por falantes nativos do inglês.

A motivação desse fato viria, então, do pressuposto de que os brasileiros aprendizes de inglês, no momento da produção das consoantes oclusivas em posição de coda silábico, tendem a realizar plenamente o segmento, o que significa dizer, no caso das oclusivas, que o falante chega a produzi-las com soltura audível, o que contrastaria com a realização feita pelo falante nativo, que, em codas silábicos, produziria a consoante oclusiva com soltura moderada ou sem soltura audível.

Considerando-se tais pressupostos, o objetivo geral deste artigo é verificar como se dá a produção das consoantes oclusivas do inglês por parte de brasileiros aprendizes de inglês como segunda língua/língua estrangeira, no que se refere à produção destas consoantes em posição de onset e coda simples em final de palavra.

\section{Características fonéticas dos sons oclusivos}

Segundo Cristófaro-Silva (1999), os segmentos consonantais correspondem aos sons que são produzidos com algum grau de fechamento do trato vocal, de modo que haja obstrução total ou parcial da passagem da corrente de ar. Quando da produção destes segmentos, pode haver vibração ou não das pregas vocais. Os segmentos consonantais são chamados de vozeados ou sonoros, quando há vibração das pregas vocais; e são chamados de desvozeados ou surdos, quando não há vibração das pregas vocais.

De acordo com Ladefoged (1993) e Johnson (1997), os sons oclusivos se caracterizam por apresentarem obstrução completa dos articuladores envolvidos quando de sua produção, de modo que a corrente de ar vinda dos pulmões é impedida de escapar pela boca. Esses sons são também chamados de plosivos, pois, quando a corrente de ar é liberada, após a obstrução, ocorre uma breve explosão no trato vocal.

As oclusivas diferem entre si quanto ao ponto de articulação, que pode ser definido como o contato entre o articulador ativo e o passivo. De acordo com Cristófaro-Silva (1999, p. 29): “Os articuladores ativos 
têm a propriedade de movimentar-se [em direção ao articulador passivo] modificando a configuração do trato vocal." Sendo assim, na produção dos sons [p] e [b], o articulador ativo é o lábio inferior e o articulador passivo é o lábio superior. Temos, portanto, oclusivas chamadas de bilabiais. $\mathrm{Na}$ produção dos sons $[\mathrm{t}$ e e [d], o articulador ativo é o ápice ou a lâmina da língua e o articulador passivo são os alvéolos. Temos, portanto, oclusivas alveolares. Finalmente, para os sons [k] e [g], o articulador ativo é a parte posterior da língua e o articulador passivo é o palato mole. Temos, assim, oclusivas chamadas de velares.

Em relação ao vozeamento, é importante apontar que esta não é uma característica predominante para a distinção dos sons oclusivos em inglês, diferente do que ocorre no PB. Em inglês, as oclusivas /p/, /t/, /k/ são sempre desvozeadas; /b/, /d/, /g/ são às vezes totalmente vozeadas, às vezes parcialmente vozeadas e, algumas vezes, se são produzidas sem vozeamento. No que concerne à posição de ataque inicial de palavra (CV), consideremos o seguinte: o que difere as oclusivas surdas das sonoras nesta posição silábica é a aspiração. Já em relação à posição de coda (VC), as oclusivas /b/, /d/, /g/ normalmente apresentam pouco vozeamento; /p/, /t/, /k/ são sempre desvozeadas.

Quanto aos traços acústicos, as oclusivas apresentam uma sequência que segue esta ordem: 1) o intervalo de silêncio; 2) a explosão; 3) e a transição de formantes. O intervalo de silêncio diz respeito à oclusão, isto é, os articuladores interrompem completamente a passagem do fluxo de ar. Segundo Kent e Read (2002), este "bloqueio articulatório" tem uma duração variável entre 50 e 100 ms. Além disso, pode-se observar durante este intervalo, através de espectrogramas, um espaço em branco, no caso das oclusivas não vozeadas ou uma concentração de energia nas baixas frequências (barra de vozeamento), no caso de algumas oclusivas vozeadas. A segunda etapa corresponde à fase de distensão da constrição, a qual apresenta características espectrais específicas que variam em função do ponto de articulação das consoantes e do contexto adjacente. Quanto à terceira etapa, dizemos que ocorre após a configuração do trato vocal se alterar desde a constrição oral durante a oclusiva para uma forma relativamente aberta para a produção do segmento seguinte.

Por se tratarem de sons que apresentam ondas aperiódicas impulsivas, 
: as oclusivas não possuem uma regularidade de repetição de vibrações, : apresentando, desta maneira, uma estrutura de natureza aleatória. Quando da produção de uma oclusiva, existe, inicialmente, um bloqueio momentâneo do trato vocal (KENT; READ, 2002), o qual provoca um curto instante de silêncio. Em seguida, ocorre um pequeno impulso, uma "explosão", denominada na literatura como "burst" (KENT; READ, 2002, p. 106). Este pequeno impulso é a realização do som consonantal.

Segundo Lisker e Abramson (1964), o momento em que as pregas vocais iniciam a vibração em relação ao momento da distensão da oclusiva é designado por voice onset time (doravante VOT). As oclusivas podem ou não apresentar a distensão. A única característica comum será um intervalo de oclusão articulatória. Quando as oclusivas em final de palavra apresentam a distensão, pode-se verificar acusticamente uma explosão breve. Por outro lado, uma vez não presente a distensão, não se observa a explosão. Este é um dos eventos acústicos mais curtos na fala, visto que não dura mais do que $10 \mathrm{~ms}$ nas oclusivas vozeadas e é um pouco mais longo nas não vozeadas (KENT; READ, 2002). Ainda segundo Halle, Hugues e Radley (1976), esse silêncio (VOT) é uma pista necessária para a percepção das oclusivas, pois, se o silêncio for preenchido por qualquer outro tipo de traço além do vozeamento, o som oclusivo não será percebido.

Ainda durante o VOT, é muito recorrente em inglês o fenômeno da aspiração, que consiste na liberação da corrente de ar durante e depois da soltura dos articuladores e, geralmente, é caracterizado por ser um momento de desvozeamento (KENT; READ, 2002). Em inglês, este fenômeno ocorre apenas com as oclusivas desvozeadas, antes ou depois de vogais tônicas. Isso significa dizer que as vogais $[\mathrm{p}]$, $[\mathrm{t}] \mathrm{e}[\mathrm{k}]$ tendem a ser pronunciadas com aspiração quando ocupam a posição de onset ou coda em sílabas tônicas, a exemplo do que acontece em tip [' $\left.\mathrm{t}^{\mathrm{h}} \mathrm{Ip}\right]$, topic ['t $\left.{ }^{\mathrm{h}} \mathrm{apI} \mathrm{k}\right]$, pack ['pæk $\mathrm{p}^{\mathrm{h}}$.

Podemos dizer que, em inglês, a duração intrínseca dos segmentos oclusivos é um fator fonologicamente determinante, pois o que diferencia as oclusivas vozeadas das não vozeadas, em posição inicial de palavra em sílabas tônicas, é a presença da aspiração na produção das surdas, e a ausência de aspiração na produção das sonoras (ROACH, 2009). Outro fator importante no que se refere à duração destes segmentos diz respeito 
ao fato de as oclusivas surdas caracterizarem-se por terem um VOT longo, ao passo que as oclusivas sonoras apresentam um VOT curto (LISKER; : ABRAMSON, 1964).

\section{O fenômeno da soltura das oclusivas em inglês}

Em relação às oclusivas em posição de coda final, em inglês, uma das ocorrências mais comuns é a não soltura audível desses segmentos (SELKIRK, 1982; DAVIDSON, 2011; PEROZZO, 2012). Este fenômeno consiste na ausência de liberação do ar pulmônico egressivo após o gesto responsável pela oclusão do ponto de articulação da respectiva consoante (PEROZZO, 2012).

A não soltura audível das oclusivas em coda finais não é uma regra categórica, uma vez que se trata de um fenômeno variável na língua inglesa. Conforme mencionado na introdução deste artigo, a manifestação fonética da não soltura audível em codas finais do inglês pode implicar dificuldades para os aprendizes brasileiros identificarem e distinguirem determinadas consoantes oclusivas na cadeia da fala. Desta forma, se a consoante final das palavras kip ['kIp], kit ['kIt], kid ['kId], kick ['kIk] for realizada sem soltura audível, brasileiros aprendizes de inglês podem não as compreender como perceptualmente distintas, visto que a não soltura da consoante oclusiva tende a diminuir o entendimento do item lexical a que se refere, o que coloca em risco a inteligibilidade das palavras (ABRAMSON; TINGSABADH, 1999).

Lisker (1999) aponta que a não soltura audível do ar após a oclusão resulta numa duração menor das consoantes oclusivas em posição de coda. Além disso, a informação acerca do ponto de articulação da consoante consonantal passa a ser fornecida pelas alterações de frequência nos formantes da vogal precedente à consoante em coda. Apesar de considerarmos a transição formântica como uma pista importante para as distinções entre os pontos de articulação das oclusivas, neste artigo, faremos uma análise apenas quanto ao fenômeno da duração destas consoantes (em onset e em coda silábicos), quando produzidas por falantes nativos do inglês em comparação com a produção dos brasileiros aprendizes de inglês. 


\section{Material e método}

: A metodologia utilizada consistiu, primeiramente, na elaboração de um corpus formado por 24 palavras em inglês, as quais apresentam estrutura silábica do tipo CVC, sendo que tanto a posição de coda quanto a posição de onset são ocupadas por consoantes oclusivas, conforme Quadro 1:

\begin{tabular}{|c|c|c|}
\hline 01 & pack & ['pæk] \\
\hline 02 & pig & ['pIg] \\
\hline 03 & pit & ['pIt] \\
\hline 04 & pub & {$[\mathrm{p} \Lambda \mathrm{b}]$} \\
\hline 05 & back & ['bæk] \\
\hline 06 & bed & ['bed] \\
\hline 07 & bet & ['bøt] \\
\hline 08 & bob & ['bab] \\
\hline 09 & tab & ['tæb] \\
\hline 10 & tag & ['tæg] \\
\hline 11 & tip & ['tip] \\
\hline 12 & tuck & {$\left[{ }^{\prime} \mathrm{t} \wedge \mathrm{k}\right]$} \\
\hline 13 & deck & ['d $\mathrm{d} k]$ \\
\hline 14 & deed & ['did] \\
\hline 15 & deep & ['dip] \\
\hline 16 & $\operatorname{dog}$ & ['dag] \\
\hline 17 & $\mathrm{cab}$ & ['kæb] \\
\hline 18 & cat & ['kæt] \\
\hline 19 & cup & ['k $\wedge \mathrm{p}]$ \\
\hline 20 & kid & ['kId] \\
\hline 21 & gap & ['gxp] \\
\hline 22 & gig & ['gIg] \\
\hline
\end{tabular}




\begin{tabular}{c|c|c}
\hline 23 & good & {$[' g \sigma d]$} \\
\hline 24 & got & ['gat $]$ \\
\hline
\end{tabular}

Quadro 1: Palavras inglesas com estrutura CVC, formadas pelas consoantes oclusivas em posição de onset e coda silábicos.

Foram selecionados três falantes nativos de inglês (os três de estados localizados a leste dos Estados Unidos - Georgia, Ohio e Massachusetts) e três falantes nativos do português e aprendizes de inglês como L2 (estudantes universitários), todos homens, sem problemas de fala e sem uso de prótese, com boa dicção e idades entre 18 e 35 anos. Os brasileiros selecionados para esta amostra são aprendizes de inglês de nível inicial, estudantes do primeiro semestre do curso de Letras da Universidade Estadual do Sudoeste da Bahia - UESB.

As palavras do Quadro 1 foram inseridas em frases-veículo do tipo (I say “ $X$ " today), transcritas individualmente em cartões brancos e apresentadas a cada informante individualmente, com um intervalo de tempo determinado entre uma frase e outra. Esses informantes foram orientados a ler cada uma das frases em voz alta da forma mais natural possível. Cada frase foi gravada três vezes aleatoriamente, para que, posteriormente, fosse feita a análise dos segmentos consonantais em posição de onset e coda, de modo a se verificar a duração dessas consoantes nessas posições.

Todas as gravações ocorreram numa câmera acusticamente isolada, no Laboratório de Pesquisa e Estudos em Fonética e Fonologia (LAPEFF), da Universidade Estadual do Sudoeste da Bahia (UESB), através de um programa de computador chamado Audacity 2.0.5, com o intuito de preservar o sinal acústico de boa qualidade. Depois disso, as palavras que constituem o corpus deste estudo foram mensuradas quanto à duração das consoantes oclusivas por meio do software Praat, desenvolvido por Boersma e Weenink (2002), o qual possibilita a segmentação da palavra da frase e a mensuração de diversos parâmetros acústicos.

Dado que a duração segmental pode variar de acordo com vários fatores (acento, qualidade vocálica, grau de ênfase, velocidade de fala, etc.), a variável mensurada neste trabalho foi a duração relativa. Neste trabalho, a duração relativa foi obtida por meio da razão entre a duração absoluta, em milissegundos, do segmento consonantal (oclusivas) sobre a duração total da palavra, multiplicada por 100. O resultado deste cálculo demonstra a 
: porcentagem de ocupação das oclusivas (tanto em posição de onset quanto : de coda) dentro da palavra.

Para analisar os dados obtidos a partir da mensuração das durações relativas, foi realizado, por meio do software de análise estatística BioEstat, versão 5.3, o teste estatístico Anova - um critério para casos em que não houve diferença de variância; e o teste Kruskal-Wallis, para casos de variâncias desiguais. Ambos os testes são usados para comparar se as médias de dois conjuntos de dados apresentam diferença significativa ou não. Por meio desses testes estatísticos, foi possível avaliar se as durações das oclusivas apresentavam diferença significativa quando ocupam a posição de onset e coda silábicos. Os valores das médias relativas foram considerados diferentes entre si para valores de $\mathrm{p} \leq 0,05 \operatorname{com} \alpha=0,05$.

\section{Resultados e discussões}

\subsection{A produção de consoantes oclusivas em posição de onset e coda silábicos por americanos}

No inglês, as oclusivas em posição de coda final de palavra tendem a ser produzidas sem uma explosão audível de ar, como em cap, fit, back, bad, led e lag (LADEFOGED, 1993) e, de acordo com trabalhos diversos (JOHNSON, 1997; CARDOSO, 2004; BECKMAN, 1990; PEROZZO, 2012), esse fenômeno acarreta diferenças duracionais dessas consoantes, se comparadas com a duração das mesmas quando estão em posição de coda medial ou em posição de onset, seja inicial ou medial.

No entanto, o fenômeno da não-soltura de consoantes oclusivas finais não se constitui como um fenômeno categórico na língua inglesa, e os dados a seguir corroboram essa análise, pois, de acordo com o parâmetro acústico de duração das consoantes oclusivas, tanto na posição de onset quanto na posição de coda (ver Tabela 1), verificamos que essas consoantes apresentam, de maneira geral, valores distintos nas duas posições quando pronunciadas por falantes nativos (americanos) do inglês.

Esses dados confirmam a nossa hipótese inicial de que os falantes nativos do inglês produziriam essas consoantes de maneiras distintas em onset e coda silábicos, porque, segundo Selkirk (1982), as consoantes oclusivas, em posição de coda final, podem variavelmente ser produzidas sem soltura audível, o que não acontece quando elas ocupam a posição de onset.

A não-soltura audível é um fenômeno fonético que consiste, basicamente, na ausência de liberação do ar pulmônico egressivo após o 
gesto responsável pelo fechamento do ponto de articulação da respectiva consoante, e isso, portanto, se revela, em nossos dados, quantitativamente pela diferença significativa das médias de duração relativa dessas oclusivas, se comparadas com as médias das mesmas em posição de onset, como pode ser visto na Tabela 1.

Tabela 1: Média da duração relativa (DR) de oclusivas em posição de onset e posição de coda realizadas por falantes nativos do inglês e respectivos valores de $p$.

\begin{tabular}{|c|c|c|c|c|}
\hline $\begin{array}{c}\text { Sujeitos } \\
\text { Americanos (SA) }\end{array}$ & Consoantes & $\begin{array}{c}\text { DR em onset } \\
(\%)\end{array}$ & $\begin{array}{l}\text { DR em } \\
\text { coda }(\%)\end{array}$ & $p$ \\
\hline \multirow{6}{*}{ SA1 } & [p] & 29,5 & 23,2 & $0,002 \mathrm{~s}$ \\
\hline & [b] & 21,0 & 22,4 & $0,91 \mathrm{~ns}$ \\
\hline & {$[t]$} & 29,0 & 23,0 & $0,021 \mathrm{~s}$ \\
\hline & [d] & 23,8 & 18,8 & $0,035 \mathrm{~s}$ \\
\hline & {$[\mathrm{k}]$} & 28,1 & 23,2 & $0,034 \mathrm{~s}$ \\
\hline & [g] & 23,3 & 19,1 & $0,032 \mathrm{~s}$ \\
\hline \multirow{6}{*}{ SA2 } & [p] & 30,4 & 24,4 & $0,008 \mathrm{~s}$ \\
\hline & [b] & 22,2 & 24,9 & $0,435 \mathrm{~ns}$ \\
\hline & {$[\mathrm{t}]$} & 27,0 & 21,8 & $0,009 \mathrm{~s}$ \\
\hline & [d] & 23,2 & 24,5 & $0,817 \mathrm{~ns}$ \\
\hline & {$[\mathrm{k}]$} & 29,6 & 25,1 & $0,006 \mathrm{~s}$ \\
\hline & [g] & 25,3 & 21,7 & $0,008 \mathrm{~s}$ \\
\hline \multirow{6}{*}{ SA3 } & [p] & 38,8 & 20,3 & $0,0001 \mathrm{~s}$ \\
\hline & [b] & 27,1 & 16,0 & $0,0001 \mathrm{~s}$ \\
\hline & {$[t]$} & 38,6 & 18,9 & $0,0001 \mathrm{~s}$ \\
\hline & [d] & 25,2 & 24,7 & $0,794 \mathrm{~ns}$ \\
\hline & {$[\mathrm{k}]$} & 38,3 & 23,7 & $0,001 \mathrm{~s}$ \\
\hline & [g] & 29,6 & 14,4 & $0,0001 \mathrm{~s}$ \\
\hline Média geral & & 28,0 & 21,0 & $0,0001 \mathrm{~s}$ \\
\hline
\end{tabular}

OBS: $\mathrm{s}=$ significativo $\mathrm{p} \leq 0,05(\boldsymbol{\alpha}=0,05)$

$$
\text { ns }=\text { não significativo } \mathrm{p} \geq 0,05(\boldsymbol{\alpha}=0,05)
$$

Fonte: elaboração própria

A Tabela 1 mostra que, de maneira geral, os valores de $p$ são significativos para os três informantes americanos desta pesquisa, o que implica dizer que, de fato, as consoantes oclusivas, quando produzidas em 
: posição de onset, ocupam uma margem bem maior da palavra do que as : oclusivas produzidas em posição de coda (média geral de $28 \%$ para o onset e $21 \%$ para a coda, $\operatorname{com} p=0,0001)$. Isso decorre provavelmente do fato de as oclusivas em posição de onset de sílaba tônica em inglês serem produzidas com aspiração, o que acarreta maior duração.

Segundo Bettoni-Techio (2005), em termos fonéticos, pode-se definir a aspiração como um intervalo de ausência de vibração das pregas vocais, após a articulação da oclusiva, havendo uma explosão de ar que ocorre durante tal período de não-vozeamento após a soltura da oclusiva.

Verifica-se claramente esse fenômeno quando observamos os efeitos na passagem entre o som oclusivo e a vogal que ocupa o núcleo da sílaba,

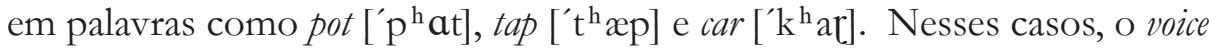
onset time (o intervalo entre a soltura da oclusiva e o início da vogal seguinte) é longo. As oclusivas aspiradas possuem caráter alofônico no inglês. Dessa forma, $\left[\mathrm{p}^{\mathrm{n}}\right],\left[\mathrm{t}^{\mathrm{t}}\right]$ e $[\mathrm{k}$ 角 são produzidas em um contexto específico: em posição inicial de palavra e em posição inicial de sílaba tônica, sem implicações fonológicas.

Voltando à análise dos dados da Tabela 1 , nota-se que existem quatro exceções. Houve, para cada sujeito americano, pelo menos uma ocorrência na qual o valor de $p$ não se mostrou significativo, o que implica dizer que a produção do segmento oclusivo em posição de coda ocupou uma margem maior da palavra do que o mesmo segmento oclusivo produzido em posição de onset. As quatro ocorrências correspondem à oclusiva bilabial sonora [b] (2 casos) e à oclusiva alveolar sonora [d] (2 casos).

Para tentar explicar esse fenômeno, cumpre observar o seguinte: uma vez que as oclusivas sonoras caracterizam-se por apresentar um VOT mais curto e as oclusivas surdas apresentam um VOT mais longo (LISKER; ABRAMSON, 1964), o que ocorreu, em nossos dados, foi a soltura audível das oclusivas sonoras [b] e [d] em posição de coda, o que acarretou maior duração segmental em algumas repetições específicas, pois, como vimos já mencionamos neste artigo, o fenômeno da não-soltura de consoantes oclusivas finais não se constitui como um algo categórico na língua inglesa. Sendo assim, o valor duracional da oclusiva sonora em coda apresentou-se maior. 
Yavas (2006, p. 59 apud Bettoni-Techio, 2005) reconhece que, em algumas variedades do inglês, as consoantes oclusivas sonoras podem : variavelmente ser realizadas com um grau maior de soltura audível em posição final. Ela explica que, na fala enfática e antes de pausa, as oclusivas em posição final de palavra podem ser produzidas com maior duração, por conta de um fator enfático. Entretanto, ao fazermos menção à produção de oclusivas (principalmente as oclusivas surdas em posição final de palavra), a tendência é que tais consoantes sejam produzidas sem soltura audível de ar (unreleased).

Para compreender esse fenômeno que ocorreu apenas com duas oclusivas sonoras no corpus aqui estudado, analisaremos, inicialmente, as figuras 1 e 2, as quais apresentam os espectrogramas das palavras bob pronunciadas em uma das repetições pelos falantes nativos de inglês, respectivamente SA1 e SA2. Observemos a ocorrência da oclusiva bilabial [b] em coda silábico.

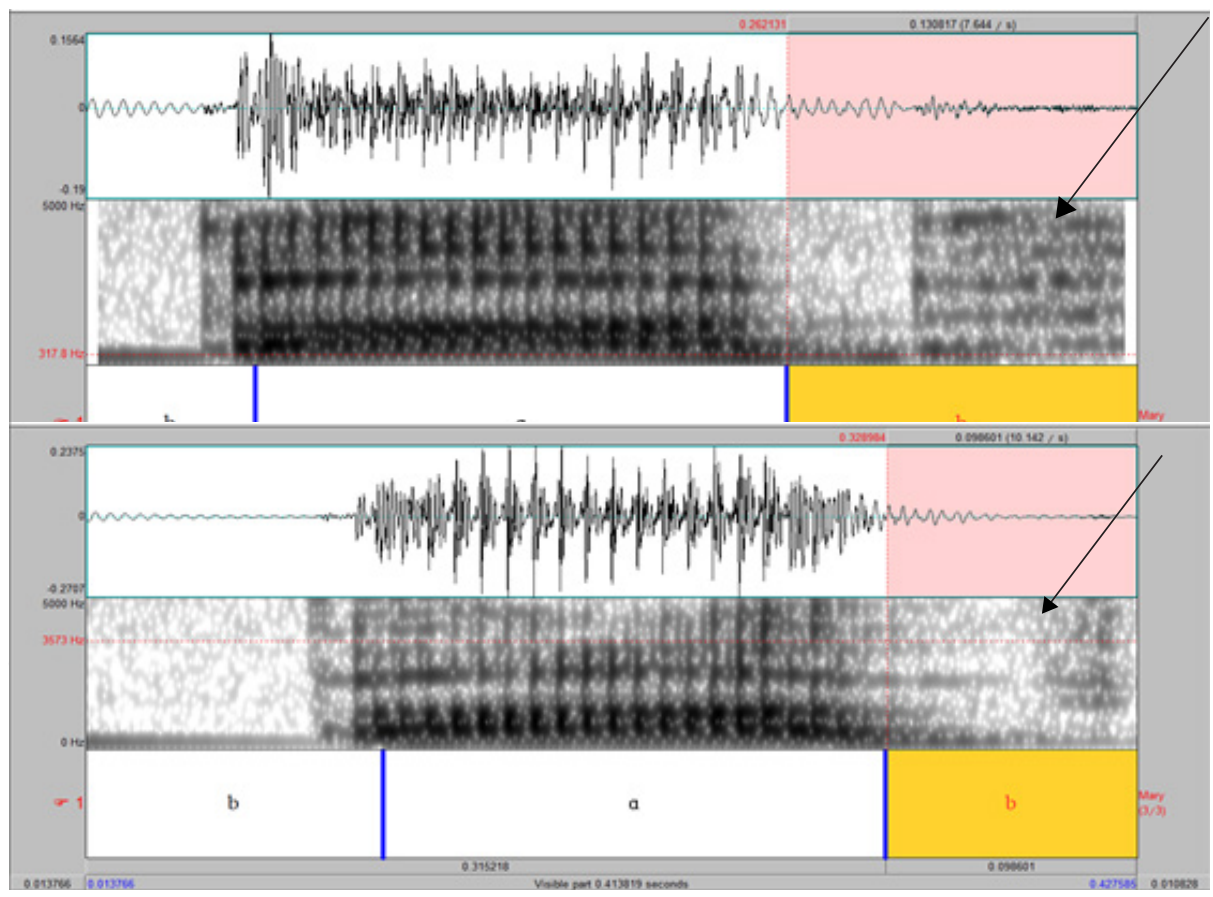

Figura 2: Espectrograma da palavra bob [’bab] pronunciada pelo falante SA1 (com soltura moderada da oclusiva bilabial sonora em posição 
de coda).

: $\quad$ No espectrograma da Figura 1, a oclusiva bilabial [b], em posição de coda, apresenta duração de $0,13 \mathrm{~ms}$, enquanto que, no espectrograma da Figura 2, a mesma oclusiva em posição de coda apresenta duração de 0,09ms. Além disso, pode-se verificar, na Figura 1, uma maior concentração de energia para a realização da oclusiva bilabial sonora em posição de coda (VOT + oclusão bem marcada com soltura audível), o que torna a oclusiva [b] mais longa do que a mesma oclusiva presente no espectrograma da Figura 2, a qual apresenta soltura moderada e uma menor concentração de energia.

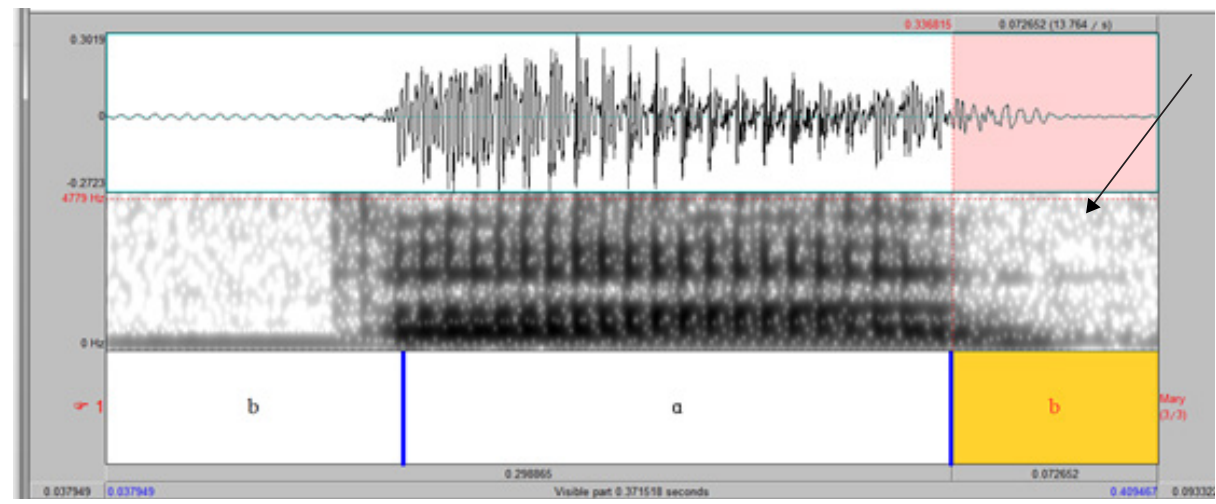

Figura 3: Espectrograma da palavra bob [’bab] pronunciada pelo falante SA3 (sem soltura audível da bilabial em posição de coda).

Por outro lado, no espectrograma da Figura 3, verifica-se a oclusiva bilabial sonora $[\mathrm{b}]$ produzida sem soltura audível em posição de coda. A oclusiva apresenta duração de $0,07 \mathrm{~ms}$ e não se faz presente uma notável concentração de energia após a produção da vogal que ocupa o núcleo da sílaba. Neste caso, conforme afirma Lisker (1999), quando da não soltura do ar após a oclusão da consoante em posição de coda final, a informação acerca do ponto de articulação do segmento consonantal é fornecida, principalmente pelas alterações de frequência nos formantes da vogal precedente à consoante em coda.

Após a análise das figuras 1, 2 e 3, podemos inferir que a duração segmental das oclusivas mantém uma relação proporcional com o fato dessas consoantes serem produzidas com soltura audível, com soltura 
moderada ou sem soltura audível. A tendência aqui observada é a de que a duração das oclusivas produzidas com soltura audível seja maior do que a duração daquelas produzidas com soltura moderada, que, por sua vez, é maior do que a duração das oclusivas produzidas sem soltura audível.

\subsection{A produção de consoantes oclusivas em posição de onset e coda silábicos por brasileiros aprendizes de inglês}

Existem, na literatura, diversos trabalhos voltados para o aprendizado de inglês como L2/LE que apontam para a possibilidade de produção de consoantes oclusivas em posição de coda com uma soltura moderada ou até mesmo sem soltura audível, a depender do nível dos aprendizes, da qualidade do input e da maneira como eles são instruídos em relação ao trabalho de pronúncia (GOAD; KANG, 2002; BETTOONI-TECHIO, 2005).

No entanto, nossos dados mostram que, para os sujeitos brasileiros aprendizes de inglês em estágio inicial, as oclusivas em posição de coda apresentam valores duracionais que são robustamente maiores do que os valores duracionais das mesmas oclusivas em posição de onset. Conforme pode-se verificar na Tabela 2, todas as médias da duração relativa das oclusivas em coda são, sem exceção, bem superiores às médias da duração relativa das oclusivas em onset.

Tabela 2: Média da duração relativa (DR) de oclusivas em posição de onset e posição de coda realizadas por brasileiros aprendizes do inglês (Nível Inicial) e respectivos valores de $p$.

\begin{tabular}{c|c|c|c|c}
\hline $\begin{array}{c}\text { Sujeitos } \\
\text { Brasileiros (SB) }\end{array}$ & Consoantes & $\begin{array}{c}\text { DR em onset } \\
\mathbf{( \% )}\end{array}$ & $\begin{array}{c}\text { DR em coda } \\
\mathbf{( \% )}\end{array}$ & $\boldsymbol{p}$ \\
\hline \multirow{4}{*}{ SB1 } & {$[\mathrm{p}]$} & 22,5 & 33,8 & $0,0001 \mathrm{~s}$ \\
\cline { 2 - 5 } & {$[\mathrm{b}]$} & 21,2 & 29,8 & $0,0002 \mathrm{~s}$ \\
\cline { 2 - 5 } & {$[\mathrm{t}]$} & 23,1 & 34,8 & $0,0001 \mathrm{~s}$ \\
\cline { 2 - 5 } & {$[\mathrm{d}]$} & 23,3 & 31,3 & $0,0001 \mathrm{~s}$ \\
\cline { 2 - 5 } & {$[\mathrm{k}]$} & 25,5 & 33,9 & $0,0001 \mathrm{~s}$ \\
\cline { 2 - 5 } & {$[\mathrm{g}]$} & 21,5 & 29,7 & $0,0015 \mathrm{~s}$ \\
\hline
\end{tabular}




\begin{tabular}{c|c|c|c|c}
\hline \multirow{4}{*}{ SB2 } & {$[\mathrm{p}]$} & 19,6 & 34,2 & $0,0001 \mathrm{~s}$ \\
\cline { 2 - 5 } & {$[\mathrm{b}]$} & 19,6 & 30,4 & $0,0001 \mathrm{~s}$ \\
\cline { 2 - 5 } & {$[\mathrm{t}]$} & 21,1 & 36,0 & $0,0001 \mathrm{~s}$ \\
\cline { 2 - 5 } & {$[\mathrm{d}]$} & 19,2 & 33,4 & $0,0001 \mathrm{~s}$ \\
\cline { 2 - 5 } & {$[\mathrm{k}]$} & 21,9 & 33,5 & $0,0001 \mathrm{~s}$ \\
\cline { 2 - 5 } & {$[\mathrm{g}]$} & 18,2 & 32,7 & $0,0001 \mathrm{~s}$ \\
\hline \multirow{4}{*}{ SB3 } & {$[\mathrm{p}]$} & 24,0 & 34,7 & $0,0001 \mathrm{~s}$ \\
\cline { 2 - 5 } & {$[\mathrm{b}]$} & 22,1 & 30,0 & $0,0001 \mathrm{~s}$ \\
\cline { 2 - 5 } & {$[\mathrm{t}]$} & 24,1 & 36,7 & $0,0001 \mathrm{~s}$ \\
\cline { 2 - 5 } & {$[\mathrm{d}]$} & 23,7 & 29,7 & $0,0009 \mathrm{~s}$ \\
\cline { 2 - 5 } & {$[\mathrm{k}]$} & 26,7 & 36,2 & $0,0001 \mathrm{~s}$ \\
\hline Média geral & {$[\mathrm{g}]$} & 21,3 & 29,6 & $0,0018 \mathrm{~s}$ \\
\hline
\end{tabular}

OBS: $\mathrm{s}=$ significativo $\mathrm{p} \leq 0,05(\alpha=0,05)$

Fonte: elaboração própria

Conforme posto inicialmente, prevíamos que os brasileiros em estágio inicial de aprendizagem produziriam as oclusivas com valores duracionais que fossem similares para a posição de onset e coda. No entanto, o que os dados da Tabela 2 revelam é que esses valores são significativamente distintos (média geral de $21 \%$ para o onset e $32 \%$ para a coda, $\operatorname{com} p=0,0001$ ). Ao compararmos as tabelas 1 e 2 , verificamos que as oclusivas em posição de coda produzidas por brasileiros aprendizes de inglês apresentam valores que são similares aos valores das oclusivas em posição de onset produzidas por falantes nativos do inglês, o que, de fato, reflete a sobreposição da fonologia do PB à do inglês no início da aprendizagem.

Dessa maneira, em posição de coda, verificamos que a duração das oclusivas é bem maior quando pronunciada por brasileiros em estágio inicial, o que reforça a nossa hipótese de que os brasileiros tendem a transferir o padrão de pronúncia de sua L1 para a L2. Nesse caso, pode-se afirmar que há uma maior duração do VOT e um gesto de articulação mais marcado se comparado com a produção do falante nativo de inglês, uma vez que, para o americano, o mais comum, nesta posição, é a ocorrência de oclusivas produzidas sem soltura audível (ou no máximo soltura audível moderada), ao passo que, para os brasileiros aprendizes de inglês em nível inicial, o que parece ser mais comum é a ocorrência de oclusivas produzidas com soltura audível.

De acordo com Goad e Kang (2002), a produção da oclusiva em 
posição de coda final com um tempo de soltura longo é mais comum na aquisição do inglês como segunda língua do que na aquisição do inglês como L1, visto que, no inglês, o mais comum é a produção desse segmento sem soltura audível; ou seja, com uma duração menor do que a duração da oclusiva em posição de onset.

Diante desses fatos, os autores supracitados atribuem a essa maior duração um papel precípuo na determinação do padrão silábico do aprendiz, uma vez que afirmam que essa soltura longa de ar é o indício fonético da formação de uma nova sílaba, em que a oclusiva é compartilhada pelo onset e pelo núcleo (Onset-Nucleus Sharing), desse modo compensado com maior duração.

Ainda segundo os autores, essa soltura longa de ar pode estar ocupando o núcleo de uma sílaba vazia extra, e, dessa forma, caracterizaria uma estratégia de reparo silábico adotada na interlíngua para "adaptar" os padrões da L2, no caso de línguas maternas em que oclusivas em coda não são permitidas, o que caracteriza uma estratégia de reparo silábico na interfonologia português-inglês (GOAD; KANG 2002).

Os dados dos informantes brasileiros aprendizes de inglês em estágio inicial são reveladores nesse sentido, pois as médias das durações relativas das oclusivas em posição de coda são certamente bem significativos. Entretanto, apesar de ainda estarem no nível inicial, os 3 primeiros informantes desta pesquisa não realizaram a epêntese como estratégia para repararem o padrão silábico não permitido pela fonotaxe do PB no momento da pronúncia de oclusivas em posição de coda no inglês, conforme supõe a proposta de Goad e Kang (2002).

Os espectrogramas a seguir ajudarão a compreender melhor o que os dados da Tabela 2 expõem.

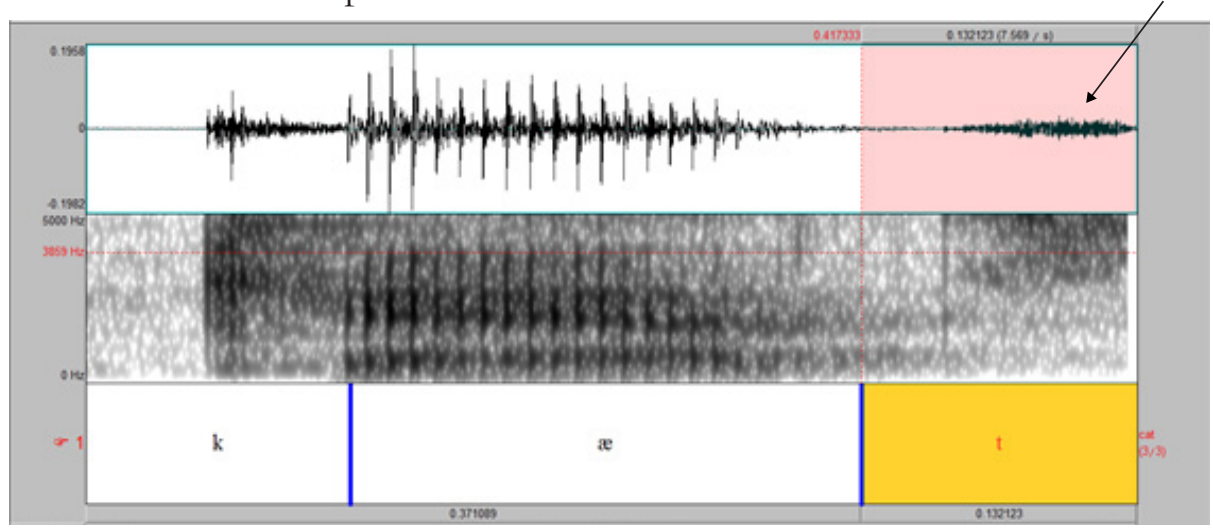


Figura 4: Espectrograma da palavra cat ['kæt] pronunciada pelo : falante SB1 (com soltura audível da oclusiva alveolar surda em posição de coda).

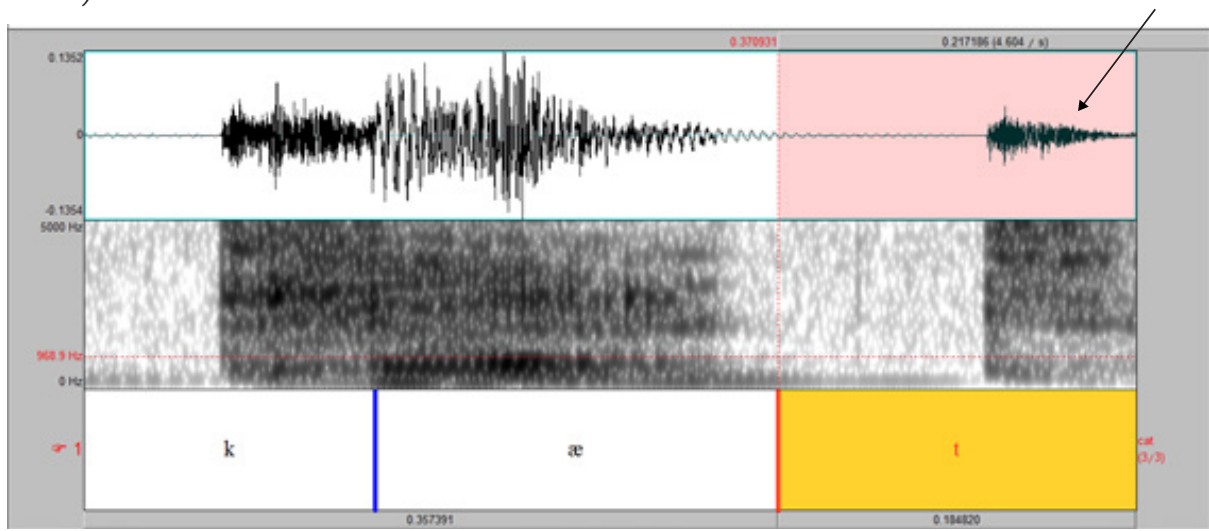

Figura 5: Espectrograma da palavra cat ['kæt] pronunciada pelo falante SB2 (com soltura audível da oclusiva alveolar surda em posição de coda).

Os espectrogramas das figuras 4 e 5 mostram que as consoantes alveolares surdas $[\mathrm{t}]$ pronunciadas em posição de coda pelos informantes brasileiros aprendizes de inglês (SB1 e SB2) apresentam valores duracionais bem longos $(0,13 \mathrm{~ms}$ e $0,18 \mathrm{~ms}$, respectivamente). Nota-se também, a partir dos formantes, que as oclusivas foram produzidas com bastante energia, o que faz com que estas consoantes apresentem soltura audível (observar o momento de explosão da oclusiva, indicado pela seta).

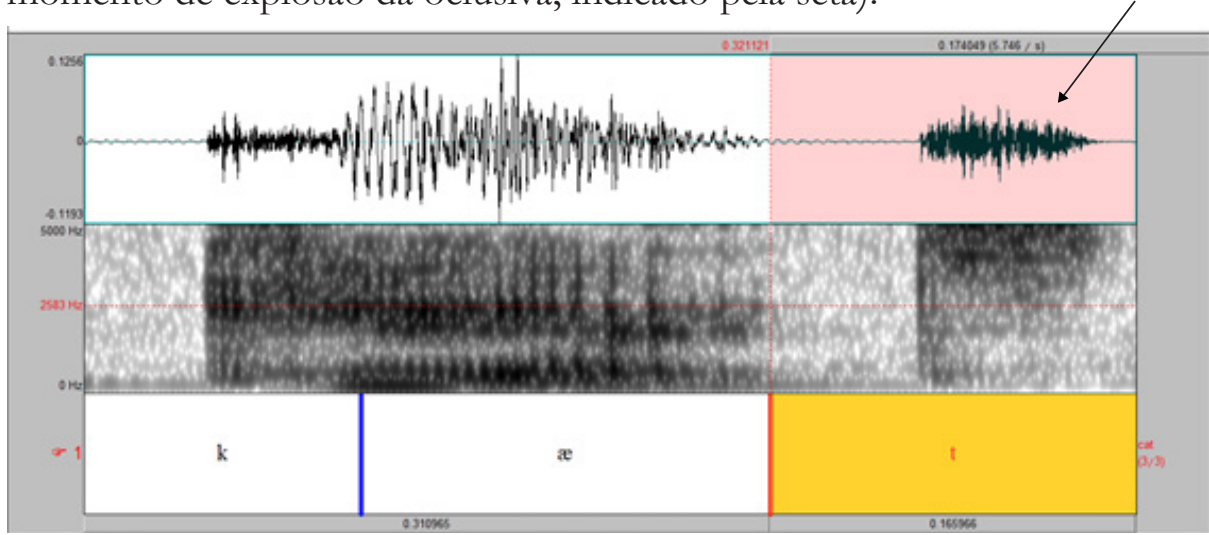

Figura 6: Espectrograma da palavra cat ['kæt] pronunciada pelo falante SB3 (com soltura audível da oclusiva alveolar surda em posição de $\operatorname{coda})$. 
Ao analisarmos o espectrograma da Figura 6, verificamos que os mesmos princípios que caracterizam a oclusiva alveolar surda [t] presente nos espectrogramas das figuras 4 e 5 se aplicam à mesma consoante apresentada na Figura 6 (duração longa, concentração de energia). Ou seja, a oclusiva alveolar surda produzida pelos informantes brasileiros apresentou soltura audível com valores duracionais longos. Além disso, apesar dos valores duracionais serem distintos $(0,013 \mathrm{~ms} / 0,018 \mathrm{~ms} / 0,016 \mathrm{~ms})$, observamos uma visível gradiência em relação à oclusão da consoante (pequena, média, grande).

Ao analisarmos os espectrogramas das figuras 7 e 8 , percebemos que a oclusiva alveolar surda [ $\mathrm{t}$ ] pronunciada por falantes nativos do inglês em posição de coda apresenta valores duracionais que são sobremaneira menores se comparados àqueles apresentados pelos brasileiros. Para os sujeitos americanos desta pesquisa, por um lado, verificou-se a ocorrência de um leve ponto que corresponde à oclusão da consoante, o que revela que essa consoante foi produzida com soltura moderada (Figura 7); por outro lado, verificou-se a ocorrência de produção da oclusiva em coda sem soltura audível (Figura 8), características comuns de produção dessas consonantes em posição de coda na língua inglesa.

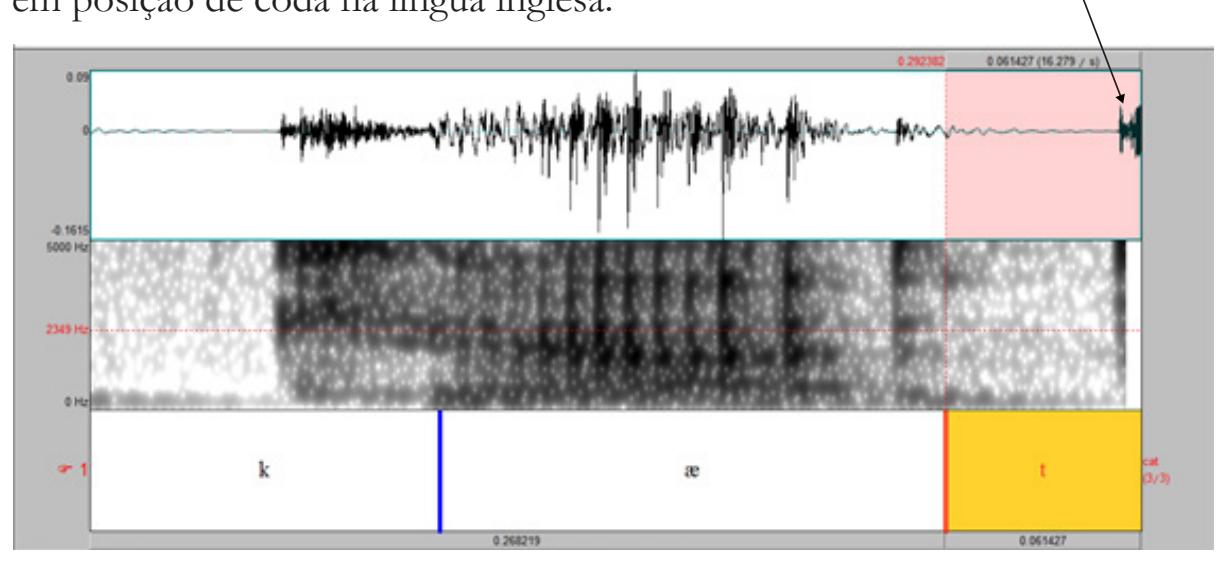

Figura 7: Espectrograma da palavra cat ['kæt] pronunciada pelo falante SA1 (com soltura moderada da oclusiva alveolar surda em posição de coda). 


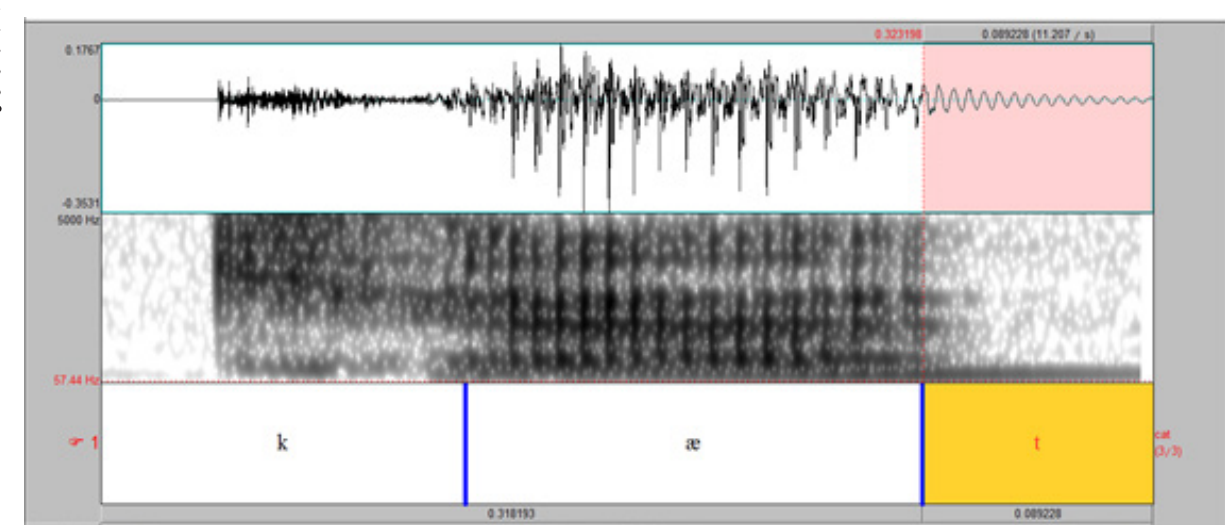

Figura 8: Espectrograma da palavra cat ['kæt] pronunciada pelo falante SA2 (sem soltura audível da oclusiva alveolar surda em posição de coda).

Em todos os espectrogramas, pudemos observar que não houve casos de epêntese (o que poderia ser esperado no caso da pronúncia dos brasileiros). Isso pode ser um indício de que, apesar da produção das oclusivas em coda por parte dos brasileiros aprendizes de inglês como L2 ser diferente da produção de um nativo, aqui nesta pesquisa, os informantes brasileiros já percebem, intuitivamente ou através de instrução explícita em escolas ou cursos de inglês, que a oclusiva quando em coda silábica não deve vir acompanhada de um segmento vocálico [I]. Ou seja, uma vez que consoantes oclusivas não são licenciadas pela fonotaxe do PB para ocorrerem em posição de coda, há uma compensação fonética no tocante à duração dessas consoantes, revelada acusticamente pela soltura audível. Esse pode ser considerado um passo importante para tentar compreender melhor o processo evolutivo do aluno quando da abordagem ensinoaprendizagem de língua inglesa.

\section{CONSIDERAÇÕES FINAIS}

Apesar dos grandes avanços que as pesquisas linguísticas e a teoria fonológica têm alcançado nas últimas décadas, muitas vezes ainda não encontramos o reflexo desses resultados, de fato, aplicados no ensino de segunda língua nas escolas e cursos brasileiros, principalmente no que diz respeito às teorias voltadas para o ensino de pronúncia. 
Aprender outra língua implica sobrepor dois sistemas fonológicos diferentes, e, quanto mais acurado o conhecimento sobre essas duas fonologias, por parte do professor, melhores serão os resultados com o aluno. Segundo Alves (2004), há de se considerar como fundamental o papel da instrução explícita no processo de ensino/aprendizagem de uma língua estrangeira, principalmente no que tange ao ensino de pronúncia.

O que os nossos dados revelaram é que, quando pronunciadas por brasileiros aprendizes de inglês, a duração das consoantes oclusivas em posição de coda supera consideravelmente a duração das oclusivas em posição de onset. Ou seja, nossa hipótese inicial de que eles produziriam tais consoantes com valores duracionais no onset próximos aos valores duracionais na coda foi refutada, já que, por não saberem como lidar fonologicamente com uma oclusiva em coda, o aprendiz brasileiro inconscientemente (por suposto) a colocaria em uma posição de ênfase fonética, o que explicaria a duração ainda maior do que as mesmas oclusivas em posição de onset.

Para os americanos, a produção das oclusivas apresenta maior duração no onset do que no coda, e isso revela que, apesar de não ser uma regra categórica no inglês, as oclusivas foram produzidas sem soltura audível na maioria das ocorrências em coda silábico, diferentemente do que acontece nas produções realizadas pelos brasileiros desta pesquisa, independentemente do nível.

Desse modo, devemos ver a produção de oclusivas com soltura audível por parte dos aprendizes como formas também possíveis na L2, e não como formas que precisam ser erradicadas em um contexto de ensinoaprendizagem. Esta, portanto, é uma ferramenta que pode ser utilizada nas aulas de língua inglesa de modo a dinamizar o aprendizado da pronúncia das codas oclusivas do inglês.

\section{REFERÊNCIAS}

ABRAMSON, A.; TINGSABADH, K. Thai Final Stops. Phonetica, 56. p. 111-122, 1999.

ALVES, U. K. O papel da instrução explícita na aquisição fonológica da L2: evidências fornecidas pela Teoria da Otimidade. 335f. Dissertação (Mestrado em Linguística). Universidade Católica de Pelotas, Pelotas, 2004. 
AVERY, P; EHRLICH, S. Teaching American English Pronunciation. Oxford:

: Oxford University Press, 1992.

BECKMAN, M. (org.) Papers in laboratory phonology 1: between the Grammar and physics of speech. New York: CUP. p. 283-333, 1990.

BETTONI-TECHIO, M. Production of final alveolar stops in Brazilian Portuguese/English interphonology. 2005. 152f. Dissertação (Mestrado em Letras). Universidade Federal de Santa Catarina, Florianópolis, 2005.

BOERSMA, P.; WEENINK, D. Praat software. Versão 4.0. The Netherlands, Amsterdam, 2002.

CARDOSO, W. Codas in Brazilian Portuguese English: A Stochastic Optimality Theory Account. Anais do Congresso Brasileiro da Associação de Fonética e Fonologia. São Luis/MA, 2004.

CRISTÓFARO-SILVA, T. Fonética e fonologia do português: Roteiro de estudos e guia de exercícios. São Paulo: Contexto, 1999.

DAVIDSON, L. Characteristics of Stop Releases in American English Spontaneous Speech. Speech Communication, 53:8, 1042-1058, 2011.

FULLANA, N.; MORA, J. C. Production and perception of voicing contrasts in English word-final obstruents: assessing the effects of experience and starting age. In: WATKINS, M. A.; RAUBER, A. S.; BAPTISTA, B. O. Recent Research in Second Language Phonetics/Phonology: Perception and Production. Cambridge Scholars Publishing, Newcastle, 2009.

GOAD, H; KANG, H. Word-final syllabification in L2 acquisition with emphasis on Korean learners of English. In: LICERAS, J. M; ZOBL, H; GOODLUCK, H. Proceedings of the 6th Generative Approaches to Second Language Acquisition Conference (GASLA 2002). Sommerville, MA: Cascadilla Proceedings Project, 2002. Disponível em: <wwwlingref.com>. Acessado em: 10 de janeiro de 2015. 
HALLE, M., HUGHES, G.; RADLEY, J. Acoustic properties of stop consonants. In: FRY, D. B. (ed). A course of basic readings. Journal of the Acoustical Society of America: Cambridge University Press. p. 162-176, 1976.

JOHNSON, K. Acoustic and Auditory Phonetics. Department of Linguistics. The Ohio State University: Blackwell Publishers, 1997.

KENT, R.; READ, C. The acoustic characteristics of consonants. In: The acoustic analysis of speech. San Diego: Singular Thomson Learning, 2002.

LADEFOGED, P. A course in Phonetics. Third edition. New York: Harcourt Brace College Publishers, 1993.

LISKER, L.; ABRAMSON, A. A Cross-language study of voicing in initial stops: acoustical measurements. Word 20. p. 384-422, 1964.

LISKER, L. Perceiving Final Voiceless Stops without Release: Effects of Preceding Monophthongs and Nonmonophthongs. Phonetica, n. 56, p. 44-55, 1999.

PEROZZO, R. V. Percep̧ão de oclusivas não vozeadas sem soltura audivel em codas finais do inglês (L2) por brasileiros: o papel do contexto fonético-fonológico, da instrução explícita e do nível de proficiência. 191f. Dissertação (Mestrado em Letras). Universidade Federal do Rio Grande do Sul, Porto Alegre, 2013.

Caracterização das oclusivas sem soltura audível na fala contínua americana. In: Anais do IV Seminário Internacional de Fonologia. Pontifícia Universidade Católica do Rio Grande do Sul: Porto Alegre, 2012.

ROACH, P. English Phonetics and Phonology: a practical course. Forth edition. Cambridge: Cambridge Press, 2009.

SELKIRK, E. The syllable. In: HULST, H. van der; SMITH, N. (ed.). The structure of phonological representations. Dordrecht: Foris. p. 337-383, 1982.

SOLÉ, M. J. Aerodynamic characteristics of onset and coda fricatives. $15^{\text {th }} \mathrm{ICPhS}$ : Universitat Autònoma de Barcelona, 2003. 